\title{
EFFECT OF CARBON EMISSION CAP ON EQUILIBRIUM OUTPUT BASED ON IS-LM-EE MODEL
}

\author{
ZHANG, M. R. ${ }^{{ }^{*}}-$ YANG, W. K. ${ }^{1}-$ LEE, C. M. ${ }^{2}-$ FAN, Q. B. ${ }^{1}$ \\ ${ }^{1}$ School of Economics, Yangtze University, Jingzhou 434020, China \\ ${ }^{2}$ Institute of Natural Resources Management, National Taipei University \\ New Taipei City 23741, Taiwan \\ *Corresponding author \\ e-mail: zhmru88@163.com \\ (Received $23^{\text {rd }}$ Nov 2017; accepted $7^{\text {th }}$ Mar 2018)
}

\begin{abstract}
Human society must strive to reduce the greenhouse gas emissions in order to control the global climate warming, but the carbon emission reduction behavior will affect the investment and consumption demand. This paper has modified the IS-LM-EE models in the existing literature. Using the new IS-LM-EE models of carbon tax system and of carbon emission cap-and-trade system, the paper analyzes the effect of the carbon emissions cap on the equilibrium output. The research results show that the carbon tax system has less impact on equilibrium output than the carbon cap-and-trade system if other conditions are the same. The carbon emissions cap and the carbon abatement investment will bring out the crowding-out effects and decrease the equilibrium output.
\end{abstract}

Keywords: cap-and-trade, carbon tax system, IS-LM-EE model, environmental macroeconomic policy, crowding-out effects

\section{Introduction}

Under the support of the world's two biggest polluters, the United States and China, the Paris Global Climate Agreement had come into force legally on the November 4, 2016 (the threshold of agreement entering into effect is that more than 55 countries of producing at least 55\% of global emissions have ratified the Paris Agreement). It is a major stride to keep global warming at a maximum of $2{ }^{\circ} \mathrm{C}$ and to pursue efforts to limit it to $1.5^{\circ} \mathrm{C}$ (UNFCCC, 2015). The objective of the Paris Agreement is to put forward the urgency of enhanced and immediate mitigation action of the climate change. In order to meet the Paris Global Climate Agreement target of staying well below $2{ }^{\circ} \mathrm{C}$ and pursuing a $1.5^{\circ} \mathrm{C}$ target, the United Nations Environment Programme (UNEP) pointed out that countries of the Intergovernmental Panel on Climate Change (IPCC) need to cut down about 12 14 billion tons of greenhouse gas emissions before 2030 based on the intended nationally determined contributions (INDCs) (UNEP, 2016).

Natural resources are limited, and the carrying capacity of the environment ultimately limits the scale of economic growth (Rezai and Stagl, 2016). In order to maintain sustained economic growth and environmental quality, we need to adopt positive environmental policies to reduce exhaustible resources consumption, waste discard and greenhouse gas emissions. The macroeconomic policy tools will promote the sustainable economic growth (Fontana and Sawyer, 2016; Halkos and Paizanos, 2015; Jackson and Victor, 2016; Rezai et al., 2013; Taylor et al., 2016; Zhang and Lee, 2017).

The mitigation action of the greenhouse gas emissions requires that environmental policy tools, financial policy tools and monetary policy tools should match and coordinate each other. Therefore, Daly (1991) constructed the theory of environmental 
macroeconomics with the environmental constraint, Heyes (2000), Lawn (2003), Sim (2006), Decker and Wohar (2012) researched the financial policy tools and monetary policy tools matching and coordinating to realize the sustainable development with the limited environmental resources by using the IS-LM-EE model. Lawn (2007) and Razmi (2016) analyzed the main role of the environmental macroeconomics policy tools in open economy. IS-LM-EE model mainly studies the decision issues of the equilibrium output and equilibrium interest rate among the equilibrium product market, equilibrium money market and equilibrium environmental market. IS curve and LM curve respectively represents the combination of different output and interest rate in the equilibrium product market and the equilibrium money market. The environment equilibrium curve (EE) serves as of all interest-output combinations when the consumed natural capital (such non-renewable resources as oil, coal, etc., or such renewable resources as lumber, river flow for hydropower, etc., or such waste discard as waste gas, waste water, waste residue discharge.) in production process exactly offsets the natural environment's ability to regenerate (or absorb) them. The relation of complementariness or substitution between the natural capital and physical capital (or manmade capital) will affect the slope of EE schedule. The environmental quality will become better (worst) when the intersection point of IS and LM curve is on the left (right) of EE curve. The economy can achieve sustainable development when the intersection point of IS and LM curve is on the EE curve. As a result, the economy achieves sustainable development.

The difference between IS-LM-EE models is that the same combination of fiscal policy and monetary policy has different effects on economic growth. For instance, the tight fiscal and expansionary monetary policy will promote economic growth on the Heyes (2000) and Sim (2006) IS-LM-EE models, but the same policy combination will lead to economic recession on Decker and Wohar (2012) IS-LM-EE model. Meanwhile, IS-LM-EE models of Heyes (2000), Lawn (2003), Decker and Wohar (2012) lack further automatic adjustment mechanism, although Sim (2006) model analyzes the automatic adjustment mechanism by using the conception of the "output gap", but the lag of adjustment mechanism will bring great threat to environmental quality.

Considering that the global warming will affect the economic sustainable development, therefore, the motive of government constraining carbon emissions cap is to promote the sustainable development of human society and economy. The government or manufacturers will invest the equipment of clean energy or technology of carbon capture and storage in order to realize the targets of carbon abatement. Assumed the fund of the government abatement investment come from carbon tax revenue and the fund of the manufacturers abatement investment come from a part of productive funds. So, the traditional analytical framework of the IS-LM-EE models have neglected the influence of manufacturers or government carbon abatement investment on IS curve.

Natural capital will provide renewable or nonrenewable resources and ecological services (such as, absorption of wastes, basic life-support functions, and amenity services) in production process (Ekins et al., 2003; Fontana and Sawyer, 2016). But the concept of natural capital is also controversial (Burkett, 2003). This paper will modify the EE curve. We use total carbon allowance to substitute the amount of natural capital in EE curve and introduce the investment of carbon abatement into EE Curve. The carbon abatement investment behavior of manufacturers or government will affect on the aggregate demand; therefore, this paper also modify the IS curve by introducing the 
investment of carbon abatement. This paper builds up the new IS-LM-EE model by using adjusted IS and EE curve and traditional LM curve and analyzes the effect of the carbon emission capon equilibrium output.

\section{Equilibrium output of new IS-LM-EE model}

\section{Constructing new IS-LM-EE model}

The new IS-LM-EE framework includes the following variables:

$Y=$ real total output

$r=$ real interest rate

$I_{\text {car }}=$ investment of carbon abatement

$\bar{E}_{c a r}=$ given carbon emissions cap

$C=$ consumption expenditures

$C_{0}=$ autonomous consumption expenditures

$G=$ autonomous government expenditures (assumed to be exogenous)

$I=$ investment expenditures

$I_{0}=$ autonomous investment expenditures

$T=$ total tax

$T R=$ government transfer expenditure

$T_{c a r}=$ total carbon tax

$\frac{M}{P}=$ real money supply

$M=$ nominal money supply

$P=$ price level (assumed to be constant)

$P_{c a r}=$ carbon tax rate or carbon price

$E=$ natural capital

$\Lambda=$ institutional parameters of environmental regulation

a) Adjusted environment equilibrium curve (EE)

The Heyes's (2000) and Sim's environment equilibrium curve (EE) equation is as follows: $E E(Y, r, E, \Lambda)=0$. It is very difficult to solve the equilibrium solution of ISLM-EE Model when EE curve is parabolic. For the convenience of analysis, We use $\bar{E}_{c a r}$ and $I_{c a r}$ respectively to substitute for $E$ and $\Lambda$ and obtain the adjusted EE curve equation: $E E\left(Y, r, \bar{E}_{c a r}, I_{c a r}\right)=0$. We expand the left side of the adjusted EE curve equation by using the first order Taylor expansion; therefore, we will obtain adjusted linear EE curve equation:

$$
\mu Y+\theta r-\zeta I_{\text {carbon }}=\bar{E}_{\text {carbon }}
$$

Equation 1 is the adjusted linear equilibrium curve (EE) with the fixed carbon emission target. Where, $\mu$ is the carbon emission intensity to the total output with given technical level, $\theta$ is the interest rate sensitivity coefficient to the carbon emissions, according to the Heyes's (2000) hypothesis of the substitute between natural capital and man-made capital, there is $\theta>0 . \zeta$ is the emissions reduction investment 
coefficient. Following Heyes's (2000) opinion, we assume that the EE curve of the negative slope is steeper than the IS curve.

The position of EE curve will be determined by the investment scale of the carbon abatement and the carbon emissions cap on the Equation 1. It will increase the more space of economic growth when the investment scale of the carbon abatement or the carbon emissions cap increases. Therefore, adjusted EE curve will move towards right, and vice versa. In order to carry out the international obligations of the reducing greenhouse gases (GHGs), some governments determine their carbon emission cap based on the intended nationally determined contributions (INDCs), but the stringent carbon abatement control goals will affect the economic growth, which is perhaps one of the reasons for the Trump administration's decision to pull out of the Paris Global Climate Agreement on June 1st 2017.

\section{b) Adjusted IS curve}

Following view of Keynes's macroeconomics, we assume that the aggregate demand consists of consumer demand, investment demand and government demand in the closed economy. Without consideration the carbon abatement investment, we can assume that the function of consumer demand, of investment demand and of government demand are respectively as follows:

Function of consumer demand (Eq. 2):

$$
C=C_{0}+c(Y-T+T R)
$$

Function of investment demand (Eq. 3):

$$
I=I_{0}-b r
$$

Function of government demand (Eq. 4):

$$
G=G
$$

Here, $c(0 \leq c<1)$ stands for the marginal propensity to consume, $b(b>0)$ stands for sensitivity coefficient of investment to interest rates. Therefore, the traditional aggregate demand function is as follows (Eq. 5):

$$
Y=C_{0}+c(Y-T+T R)+\left(I_{0}-b r\right)+G
$$

Case one:

If we assume that the government takes on the carbon abatement investment responsibility by levied carbon tax with the manufacturers according to the polluter paying principle, and the total carbon tax revenue are used in the activity of government carbon abatement investment and the manufacturers do not invest the carbon abatement activity. Namely, $I_{c a r}=T_{c a r}$. Meanwhile, the function of investment demand and of government demand will be unchanged.

So, the adjusted function of consumer demand is as follows (Eq. 2a): 


$$
C=C_{0}+c\left(Y-T-T_{c a r}+T R\right)
$$

Equation 5 will change as follows (Eq. 5a):

$$
Y=C_{0}+c\left(Y-T-I_{c a r}+T R\right)+\left(I_{0}-b r\right)+G
$$

Namely, adjusted IS curve equation is as follows $(E q .6 a)$ :

$$
(1-c) Y+b r+c I_{c a r}=C_{0}+I_{0}+c T R+G-c T
$$

Case two:

If we assume that the government encourage the manufacturers to invest carbon abatement activity by the carbon cap-and-trade system, and the manufacturer investment will be divided into productive investment and emission abatement investment. The emission abatement investment is unproductive investment, to increase the emission abatement investment increasing means the productive investment decreasing when the total capital is fixed. Meanwhile, the function of consume demand and of government demand will be unchanged.

The adjusted function of investment demand is as follows (Eq. $3 a)$ :

$$
I=I_{0}-b r-I_{c a r}
$$

Therefore, Equation 5 will change as follows (Eq. 5b):

$$
Y=C_{0}+c(Y-T+T R)+\left(I_{0}-b r-I_{c a r}\right)+G
$$

Namely, adjusted IS curve equation is as follows $(E q .6 b)$ :

$$
(1-c) Y+b r+I_{c a r}=C_{0}+I_{0}+c T R+G-c T
$$

Equation $6 a$ or $6 b$ is the adjusted IS curve with the investment of carbon emission reduction.

Obviously, the investment scale of the carbon abatement will determine the position of IS curve.

\section{c) LM curve}

In order to facilitate the analysis, we still adopt the traditional LM curve in the money market (Eq. 7):

$$
g Y-h r=\frac{M}{P}
$$

Where, $g(g>0)$ is the sensitivity coefficient of money demand to national income, $h(h>0)$ is the sensitivity coefficient of money demand to the real interest rate. 


\section{d) New IS-LM-EE model}

Case one:

Equations 1, $6 a$ and 7 constitute new IS-LM-EE model based on the carbon tax system. The model is as follows $(E q .8 a)$ :

$$
\left\{\begin{array}{c}
(1-c) Y+b r+c I_{c a r}=C_{0}+I_{0}+c T R+G-c T \\
g Y-h r=\frac{M}{P} \\
\mu Y+\theta r-\zeta I_{c a r}=\bar{E}_{c a r}
\end{array}\right.
$$

Case two:

Equations 1, $6 b$ and 7 constitutes new IS-LM-EE model based on the carbon capand-trade system. The model is as follows $(E q .8 b)$ :

$$
\left\{\begin{array}{c}
(1-c) Y+b r+I_{c a r}=C_{0}+I_{0}+c T R+G-c T \\
g Y-h r=\frac{M}{P} \\
\mu Y+\theta r-\zeta I_{c a r}=\bar{E}_{c a r}
\end{array}\right.
$$

\section{Equilibrium solution of the IS-LM-EE model}

In the systems of equations (Eq. $8 a)$, we obtain the equilibrium solution of output, interest rate and investment of carbon abatement (Eqs. 9a, 10a, 11a):

$$
\begin{gathered}
Y_{t a x}=\frac{\zeta h A_{0}+(\zeta b+c \theta) \frac{M}{P}+c h \bar{E}_{c a r}}{c g \theta+\mu c h+\zeta g b+\zeta h(1-c)} \\
r_{t a x}=\frac{\zeta g A_{0}-[c \mu+\zeta(1-c)] \frac{M}{P}+c g \bar{E}_{c a r}}{c g \theta+\mu c h+\zeta g b+\zeta h(1-c)} \\
I_{c a r}^{t a x}=\frac{(g \theta+\mu h) A_{0}+[\mu b-\theta(1-c)] \frac{M}{P}-[g b+h(1-c)] \bar{E}_{c a r}}{c g \theta+\mu c h+\zeta g b+\zeta h(1-c)}
\end{gathered}
$$

In order to assure the nonnegative investment of carbon abatement, we assume (Eq. 12a):

$$
I_{c a r}^{\operatorname{tax}}=\frac{(g \theta+\mu h) A_{0}+[\mu b-\theta(1-c)] \frac{M}{P}-[g b+h(1-c)] \bar{E}_{c a r}}{c g \theta+\mu c h+\zeta g b+\zeta h(1-c)} \geq 0
$$


In the systems of equations $(E q .8 b)$, we obtain the equilibrium solution of output, interest rate and investment of carbon abatement (Eqs. 9b, 10b, 11b):

$$
\begin{gathered}
Y_{\text {trade }}=\frac{\zeta h A_{0}+(\zeta b+\theta) \frac{M}{P}+h \bar{E}_{c a r}}{g \theta+\mu h+\zeta g b+\zeta h(1-c)} \\
r_{\text {trade }}=\frac{\zeta g A_{0}-[\mu+\zeta(1-c)] \frac{M}{P}+g \bar{E}_{c a r}}{g \theta+\mu h+\zeta g b+\zeta h(1-c)} \\
I_{\text {car }}^{\text {trade }}=\frac{(g \theta+\mu h) A_{0}+[\mu b-\theta(1-c)] \frac{M}{P}-[g b+h(1-c)] \bar{E}_{c a r}}{g \theta+\mu h+\zeta g b+\zeta h(1-c)}
\end{gathered}
$$

In order to assure the nonnegative investment of carbon abatement, we assume (Eq. 12b):

$$
I_{\text {car }}^{\text {trade }}=\frac{(g \theta+\mu h) A_{0}+[\mu b-\theta(1-c)] \frac{M}{P}-[g b+h(1-c)] \bar{E}_{c a r}}{g \theta+\mu h+\zeta g b+\zeta h(1-c)} \geq 0
$$

Obviously, there is $Y_{\text {tax }} \geq Y_{\text {trade }}$ and $I_{c a r}^{\text {tax }} \geq I_{\text {car }}^{\text {trade }}$ when $0 \leq c<1$. This shows that it has less impact on equilibrium output when the government takes on the carbon abatement investment responsibility by levied carbon tax with the manufacturers.

We assume that the carbon tax rate is $P_{c a r}$. Based on the previous analysis, the real carbon emissions of the manufacturer is $\zeta I_{c a r}+\bar{E}_{c a r}$. So, the total carbon tax revenue is $T_{c a r}=I_{c a r}=P_{c a r} \times\left(\zeta I_{c a r}+\bar{E}_{c a r}\right)$. Therefore, the carbon tax rate must be satisfied (Eq. 13):

$$
P_{c a r}=\frac{1}{\zeta+\frac{[c g \theta+\mu c h+\zeta g b+\zeta h(1-c)] \bar{E}_{c a r}}{(g \theta+\mu h) A_{0}+[\mu b-\theta(1-c)] \frac{M}{P}-[g b+h(1-c)] \bar{E}_{c a r}}}
$$

Equation 13 shows that the carbon tax rate will be affected by fiscal policy, or the monetary policy, or the carbon emission goal. For example, the carbon tax rate will increase when the government implements the expansionary fiscal policy, or expansionary monetary policy, or decreasing the carbon emission cap. But the carbon tax rate will be very difficult to change in the short period when the government levies the carbon tax to the manufacturer with the fixed carbon tax rate. The new IS-LM-EE model with the carbon tax system will be very difficult to realize new equilibrium with the change of the environmental macroeconomic policy tool. But the new IS-LM-EE model with the cap-and-trade system will automatically realize the new equilibrium with the change of the environmental macroeconomic policy tool. In this sense, the manufacturer 
taking on the carbon abatement investment responsibility is better than the government taking on the carbon abatement investment responsibility by levied carbon tax.

\section{Crowding-out effects of the carbon emissions cap on the new IS-LM-EE model}

IS curve and LM curve will decide equilibrium output and the carbon abatement investment is null if the government does not restrain the carbon emissions cap. The equilibrium output is as follows (Eq. 14):

$$
Y^{*}=\frac{h A_{0}+b \frac{M}{P}}{(1-c) h+b g}
$$

Owing to the government restrains the carbon emissions cap and the carbon abatement investment is unproductive investment, the carbon emissions cap and the carbon abatement investment will bring out the crowding-out effects and decrease the equilibrium output.

Let, $\Delta Y_{\text {tax }}=Y^{*}-Y_{\text {tax }}, \Delta Y_{\text {trade }}=Y^{*}-Y_{\text {trade }}$.

Therefore (Eqs. 15 and 16):

$$
\begin{gathered}
\Delta Y_{\text {tax }}=\frac{(g \theta+\mu h) c h A_{0}+[\mu b-(1-c) \theta] c h \frac{M}{P}-[(1-c) h+b g] c h \bar{E}_{c a r}}{[c g \theta+\mu c h+\zeta g b+\zeta h(1-c)][(1-c) h+b g]} \\
\Delta Y_{\text {trade }}=\frac{(g \theta+\mu h) h A_{0}+[\mu b-(1-c) \theta] h \frac{M}{P}-[(1-c) h+b g] h \bar{E}_{c a r}}{[g \theta+\mu h+\zeta g b+\zeta h(1-c)][(1-c) h+b g]}
\end{gathered}
$$

Obviously, there is $\Delta Y_{\text {tax }}<\Delta Y_{\text {trade }}$ when $0 \leq c<1$. This shows that the crowding-out effects of carbon tax system is less than of carbon cap-and-trade system.

\section{Environmental macroeconomic policy analysis in the new IS-LM-EE model}

The equilibrium solutions have the similar form in two kinds of new IS-LM-EE model. So we only analyze the effect of any environmental macroeconomic policy tools change in the new IS-LM-EE model with the carbon cap-and-trade system.

According to the hypothesis, the EE curve of the downward sloping is steeper than IS curve of, namely, $-\frac{\mu}{\theta}<-\frac{1-c}{b}, \theta>0$.

\section{Expansionary fiscal policy}

The derivatives of Equations $9 b$ and $11 b$ on government expenditures $G$ are as follows:

$$
\frac{d Y_{\text {trade }}}{d G}=\frac{\zeta h}{g \theta+\mu h+\zeta g b+\zeta h(1-c)}>0
$$




$$
\frac{d I_{\text {cade }}^{\text {trade }}}{d G}=\frac{g \theta+\mu h}{g \theta+\mu h+\zeta g b+\zeta h(1-c)}>0
$$

Equations 17 and 18 show that the equilibrium output and the equilibrium investment of the carbon abatement will increase when the government implements the expansionary fiscal policy by enlarging the government purchase expenditure.

As shown in Figure 1, $\mathrm{IS}_{0}, \mathrm{LM}$ and $\mathrm{EE}_{0}$ curve will achieve the equilibrium in point A. The IS curve will shift to the right from the $\mathrm{IS}_{0}$ to $\mathrm{IS}_{2}$ when the government implements the expansionary fiscal policy, so the expansionary fiscal policy will increase total output, also increases of carbon emission, so the manufacturer needs to increase the investment of carbon abatement, so, the EE curve also shift to the right, the IS curve starts to shift to left from the IS ${ }_{2}$ to IS $_{1}$ when the manufacturers increase the investment of the carbon abatement. The $\mathrm{IS}_{1}, \mathrm{LM}$ and $\mathrm{EE}_{1}$ curve will achieve new equilibrium at the point $B$.

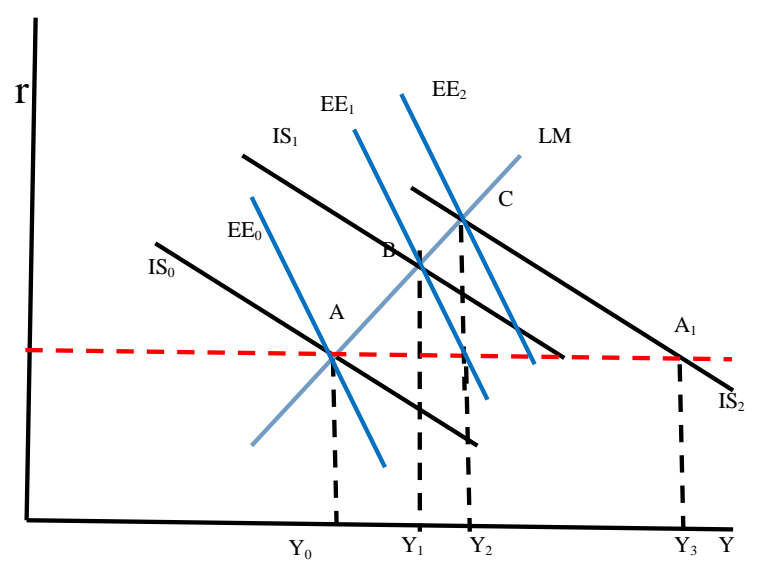

Figure 1. Expansionary fiscal policy

\section{Expansionary monetary policy}

The derivatives of Equations $9 b$ and $11 b$ on money supply are as follows:

$$
\begin{gathered}
\frac{d Y_{\text {trade }}}{d M}=\frac{\zeta b+\theta}{P} \frac{1}{g \theta+\mu h+\zeta g b+\zeta h(1-c)}>0 \\
\frac{d I_{\text {car }}^{\text {trade }}}{d M}=\frac{\mu b-\theta(1-c)}{P} \frac{1}{g \theta+\mu h+\zeta g b+\zeta h(1-c)}>0
\end{gathered}
$$

Equations 19 and 20 show that the equilibrium total output and the equilibrium investment of the carbon abatement will increase when the government implements the expansionary monetary policy by enlarging the money supply.

As shown in Figure 2, IS $0, \mathrm{LM}_{0}$ and $\mathrm{EE}_{0}$ curve will achieve the equilibrium in point A. The LM curve will shift to the right from the $\mathrm{LM}_{0}$ to $\mathrm{LM}_{1}$ when the government implements the expansionary monetary policy by increasing nominal money supply, the total output increasing will lead to the carbon emission increasing, so the manufacturer needs to increase the investment of carbon abatement, the EE curve also shifts to the 
right, the IS curve starts to shift to left from the IS $S_{1}$ to $I_{0}$ when the manufacturers increase the investment of carbon abatement. The $\mathrm{IS}_{1}, \mathrm{LM}_{1}$ and $\mathrm{EE}_{1}$ curve will achieve new equilibrium at the point $\mathrm{B}$.

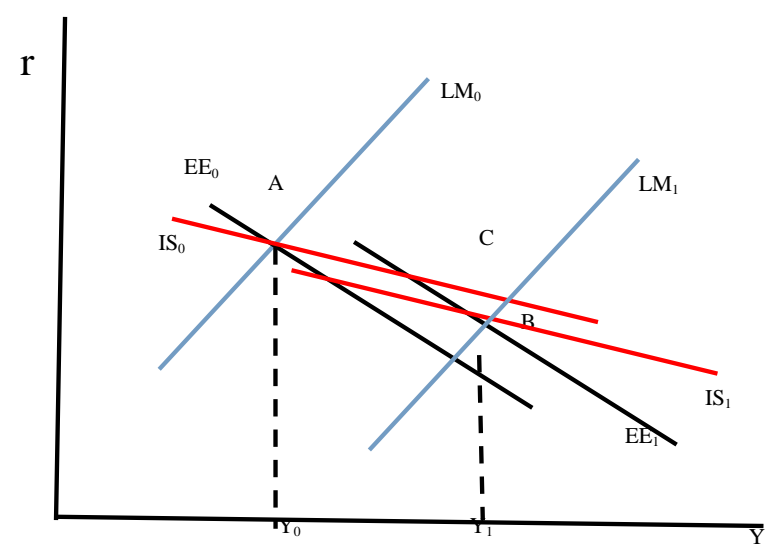

Figure 2. Expansionary monetary policy

\section{Raising carbon emissions cap}

The derivatives of Equations $9 b$ and $11 b$ on carbon emissions cap are as follows:

$$
\begin{aligned}
& \frac{d Y_{\text {trade }}}{d \bar{E}_{\text {car }}}=\frac{h}{g \theta+\mu h+\zeta g b+\zeta h(1-c)}>0 \\
& \frac{d I_{\text {car }}^{\text {trade }}}{d \bar{E}_{c a r}}=\frac{-[g b+h(1-c)]}{g \theta+\mu h+\zeta g b+\zeta h(1-c)}<0
\end{aligned}
$$

Equation 21 shows that the equilibrium output will increase when the government increases the carbon emissions cap. Equation 22 shows that the investment of the carbon emission reduction will decrease when the government increases the carbon emissions cap.

As shown in Figure 3, $\mathrm{IS}_{0}, \mathrm{LM}_{0}$ and $\mathrm{EE}_{0}$ curve will achieve the equilibrium in point A.

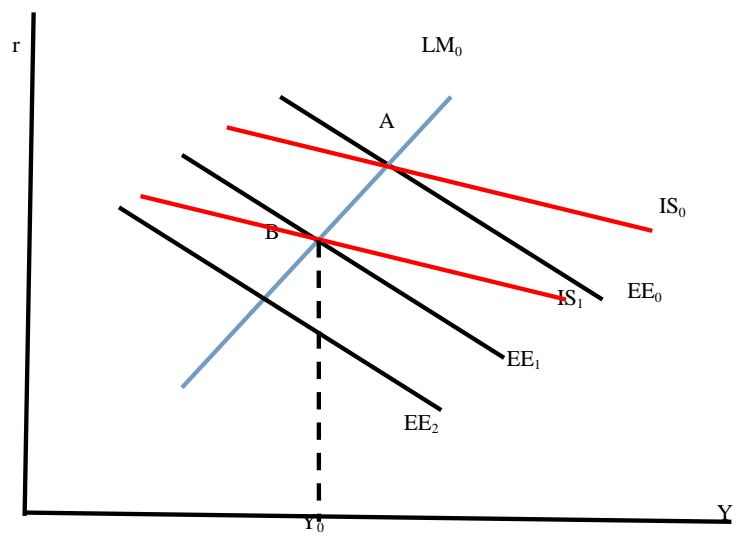

Figure 3. Decrease carbon emissions cap 
The $\mathrm{EE}_{0}$ curve will shift to the left to the position of $\mathrm{EE}_{2}$ curve when the government decreases the carbon emissions cap. The carbon emission in production process at the intersection $\mathrm{A}$ of the $\mathrm{IS}_{0}$ curve and $\mathrm{LM}_{0}$ curve will exceed the given carbon emission cap, so the manufacturer needs to increase the investment of the carbon abatement, the $\mathrm{EE}_{2}$ curve will shift to the right to the position of $\mathrm{EE}_{1}$ curve. Owing to increasing the investment of the carbon emission reduction, the IS curve start to shift to left from the $\mathrm{IS}_{0}$ to $\mathrm{IS}_{1}$. The $\mathrm{IS}_{1}, \mathrm{LM}_{0}$ and $\mathrm{EE}_{1}$ curve will achieve new equilibrium at the point $\mathrm{B}$.

\section{Macroeconomic policy tools portfolio}

Next, we research the effect of the environmental macroeconomic policy portfolio on the equilibrium output with the fixed carbon emissions cap and the unchanged investment of the carbon emission reduction.

The perfect differential of Equations $9 b$ and $11 b$ are as follows (Eqs. 23 and 24):

$$
\begin{gathered}
d Y_{\text {trade }}=\frac{\zeta h d A_{0}+(\zeta b+\theta) \frac{d M}{P}+h d \bar{E}_{c a r}}{g \theta+\mu h+\zeta g b+\zeta h(1-c)} \\
d I_{\text {car }}^{\text {trade }}=\frac{(g \theta+\mu h) d A_{0}+[\mu b-\theta(1-c)] \frac{d M}{P}-[g b+h(1-c)] d \bar{E}_{c a r}}{g \theta+\mu h+\zeta g b+\zeta h(1-c)}
\end{gathered}
$$

If we assume that the fixed carbon emissions cap and the investment of the carbon emission reduction remain unchanged, and the government implements the expansionary fiscal policy by enlarging the government purchase expenditure. Therefore, $\quad d A_{0}=d G \quad, \quad d I_{\text {car }}^{\text {trade }}=d \bar{E}_{c a r}=0 \quad, \quad \frac{d M}{P}=-\frac{(g \theta+\mu h) d G}{\mu b-\theta(1-c)} \quad, \quad$ and $d Y_{\text {trade }}=\frac{-[\zeta h(1-c)+\zeta b g+g \theta+\mu h] \theta d G}{[g \theta+\mu h+\zeta g b+\zeta h(1-c)][\mu b-\theta(1-c)]}$.

This shows that the expansionary fiscal policy needs to collocate tight monetary policy when the fixed carbon emissions cap and the investment of the carbon emission reduction remain unchanged. The expansionary fiscal and tight monetary policy portfolio decreases the equilibrium output, vice versa. This conclusion is similar to the implication of macroeconomic policy portfolio on Heyes's IS-LM-EE model.

\section{Conclusion}

This paper revises the IS curve and EE curve under the constraint of given carbon emission cap and the investment of carbon abatement based on previous studies, and sets up two kinds of the IS-LM-EE model with carbon tax system and the IS-LM-EE model with carbon cap-and-trade system. The research results show that the equilibrium output of carbon tax system is more than of carbon emission cap-and-trade system. But the new equilibrium will be very difficult to realize with the fixed carbon tax rate in the IS-LM-EE model with carbon tax system when the environmental macroeconomic policy instruments change; however, the new equilibrium will automatic realize in the IS-LM-EE model with carbon cap-and-trade system at same condition. Thus, the carbon 
cap-and-trade system is more reasonable and practicable than the carbon tax system in practice. The new IS-LM-EE models will automatically achieve new equilibrium by adjusting the investment scale of the carbon abatement when any policy tool of environmental macroeconomic policy changes. There exists the crowding-out effects of the investment of the carbon abatement in the new IS-LM-EE model. The expansionary fiscal policy needs to collocate tight monetary policy when the fixed carbon emissions cap and the investment of the carbon emission reduction remain unchanged. This policy portfolio will decrease the equilibrium output, vice versa.

The conclusion of this paper is based on Heyes's (2000) hypothesis of the substitute between natural capital and man-made capital and the EE curve of the negative slope being steeper than the IS curve. The conclusion can be changed if the hypothesis of the substitute between natural capital and man-made capital, or of the negative slope EE curve being steeper than the IS curve changes. Thus, we need to study the effect of carbon emission cap on equilibrium output with complementarity between natural capital and man-made capital in new IS-LM-EE model. We also need to study the effect of carbon emission cap on equilibrium output with new IS-LM-EE model in the open economy in the future.

Acknowledgements. The authors are deeply grateful to APPLIED ECOLOGY AND ENVIRONMENTAL RESEARCH editor and two anonymous reviewers for their valuable comments. This work was supported by the grant from research and development foundation for humanities and social sciences of Yangtze University [Project No. 2017cszb06].

\section{REFERENCES}

[1] Burkett, P. (2003). Natural capital, ecological economics and Marxism. - Int. Pap. Polit. Econ. 10(3): 1-62.

[2] Daly, H. E. (1991): Towards an environmental macroeconomics. - Land Economics 67(2): 255-259.

[3] Decker, C. S., Wohar, M. E. (2012): Substitutability or complementarity? Re-visiting Heyes' IS-LM-EE model. - Ecological Economics 74: 3-7.

[4] Ekins, P., Simon, S., Deutsch, L., Folke, C., De Groot, R. (2003). A framework for the practical application of the concepts of critical natural capital and strong sustainability. Ecological Economics 44(2-3): 165-185.

[5] Fontana, G., Sawyer, M. (2016): Towards post-Keynesian ecological macroeconomics. Ecological Economics 121: 186-195.

[6] Halkos, G., Paizanos, E. (2015): Environmental macroeconomics: A critical literature review and future empirical research directions. - https://mpra.ub.unimuenchen.de/67432/1/MPRA_paper_67432.pdf.

[7] Heyes, A. (2000): A proposal for the greening of textbook macro: "IS-LM-EE". Ecological Economics 32(1): 1-7.

[8] Jackson, T., Victor, P. A. (2016): Does slow growth lead to rising inequality? Some theoretical reflections and numerical simulations. - Ecological Economics 121: 206-219.

[9] Lawn, P. (2007): Increasing Sustainable National Income by Restoring Comparative Advantage as the Principle Governing International Trade. Frontier Issues in Ecological Economics. - Edward Elgar Publishing, Cheltenham, UK and Northampton, MA, USA.

[10] Lawn, P. A. (2003): On Heyes' IS-LM-EE proposal to establish an environmental macroeconomics. - Environment and Development Economics 8(1): 31-56.

[11] Razmi, A. (2016): The macroeconomics of emission permits: simple stylized frameworks for short-run policy analysis. - Eastern Economic Journal 42(1): 29-45. 
[12] Rezai, A., Stagl, S. (2016): Ecological macroeconomics: Introduction and review. Ecological Economics 121: 181-185.

[13] Rezai, A., Taylor, L., Mechler, R. (2013): Ecological macroeconomics: An application to climate change. - Ecological Economics 85: 69-76.

[14] Sim, N. C. (2006): Environmental Keynesian macroeconomics: some further discussion. Ecological Economics 59(4): 401-405.

[15] Taylor, L., Rezai, A., Foley, D. K. (2016): An integrated approach to climate change, income distribution, employment, and economic growth. - Ecological Economics 121: 196-205.

[16] United Nations Environment Programme (UNEP) (2016): The Emissions Gap Report. A UNEP Synthesis Report, 2016. http://uneplive.unep.org/media/docs/theme/13/Emissions_Gap_Report_2016.pdf.

[17] UNITED NATIONS, PARIS AGREEMENT http://unfccc.int/files/essential_background/convention/ application /pdf/english_paris_agreement.pdf.

[18] Zhang, M., Lee, C. (2017): Economic policy of sustainable development based on ISLM-EE model. - Applied Ecology and Environmental Research 15(3): 785-795. 